\title{
ERRATUM
}

\section{Distribution of phthalate esters in the groundwater of Jianghan plain, Hubei, China}

\author{
Dan ZHANG, Hui LIU (凶), Ying LIANG, Cheng WANG, Hecheng LIANG, Hesheng CAI
}

Key Laboratory of Biogeology and Environmental Geology of Ministry of Education, School of Environmental Studies, China University of Geosciences, Wuhan 430074, China

(C) Higher Education Press and Springer-Verlag 2009

Erratum to: Front. Earth Sci. China 2009, 3(1): 73-79

DOI 10.1007/s11707-009-0017-5

A few mistakes have been made due to typesetting errors. The Editorial Office regrets these errors.

The units on longitudinal axis of Figs. 4-7 were incorrect.

The correct units should be "/(ng $\left.\cdot \mathrm{L}^{-1}\right)$ ".

The online version of the original article can be found at http://dx.doi.org/10.1007/s11707-009-0017-5

Received May 20, 2008; accepted November 4, 2008

E-mail: zliuhui@hotmail.com 